\title{
THE EFFECT OF PARTICLE INLET CONDITIONS ON FCC RISER HYDRODYNAMICS AND PRODUCT YIELDS*
}

\author{
S.L. Chang, B. Golchert, S.A. Lottes,
}

C.Q. Zhou, ${ }^{* *}$ A. Huntsinger, ${ }^{* *}$ and M. Petrick

Argonne National Laboratory

9700 South Cass Avenue

Argonne, IL 60439

** Purdue University Calumet Hammond, IN 46323

Submitted to

1999 International Mechanical Engineering Congress and Exposition,

Nov. 14-19, 1999, Nashville, TN sponsored by

the K-6 committee of the Heat Transfer Division of ASME.

* Work supported by U.S. Department of Energy, Office of Energy Efficiency and Renewable Energy and the Office of Industrial Technologies, under Contract W-31-109ENG-38. 


\section{DISCLAIMER}

This report was prepared as an account of work sponsored by an agency of the United States Government. Neither the United States Government nor any agency thereof, nor any of their employees, make any warranty, express or implied, or assumes any legal liability or responsibility for the accuracy, completeness, or usefulness of any information, apparatus, product, or process disclosed, or represents that its use would not infringe privately owned rights. Reference herein to any specific commercial product, process, or service by trade name, trademark, manufacturer, or otherwise does not necessarily constitute or imply its endorsement, recommendation, or favoring by the United States Government or any agency thereof. The views and opinions of authors expressed herein do not necessarily state or reflect those of the United States Government or any agency thereof. 


\section{DISCLAIMER}

\section{Portions of this document may be illegible in electronic image products. Images are produced from the best available original document.}




\title{
THE EFFECT OF PARTICLE INLET CONDITIONS ON FCC RISER HYDRODYNAMICS AND PRODUCT YIELDS*
}

\author{
S.L. Chang, B. Golchert, S.A. Lottes, \\ C.Q. Zhou, ${ }^{*}$ A. Huntsinger, ${ }^{*}$ and M. Petrick \\ Argonne National Laboratory \\ 9700 South Cass Avenue \\ Argonne, llinois 60439 \\ *Purdue University Calumet \\ Hammond, Indiana 46323
}

\begin{abstract}
Essential to today's modern refineries and the gasoline production process are fluidized catalytic cracking units. By using a computational fluid dynamics (CFD) code developed at Argonne National Laboratory to simulate the riser, parametric and sensitivity studies were performed to determine the effect of catalyst inlet conditions on the riser hydrodynamics and on the product yields. Simulations were created on the basis of a general riser configuration and operating conditions. The results of this work are indications of riser operating conditions that will maximize specific product yields. The CFD code is a three-dimensional, multiphase, turbulent, reacting flow code with phenomenological models for particle-solid interactions, droplet evaporation, and chemical kinetics. The code has been validated against pressure, particle loading, and product yield measurements. After validation of the code, parametric studies were performed on various parameters such as the injection velocity of the catalyst, the angle of injection, and the particle size distribution. The results indicate that good mixing of the catalyst particles with the oil droplets produces a high degree of cracking in the riser.
\end{abstract}

\section{NOMENCLATURE}

$\mathrm{a}_{\mathrm{i}} \quad$ stoichiometric coefficients for Reaction (a)

$b_{i} \quad$ stoichiometric coefficients for Reaction (b)

$\mathrm{C}_{\mathrm{d}} \quad$ drag coefficient

$\mathrm{C}_{\mathrm{k}} \quad$ coke species

$\mathrm{Cp} \quad$ specific heat $(\mathrm{J} / \mathrm{kg} / \mathrm{K})$

$\mathrm{f}_{\mathrm{i}} \quad$ species mass fraction

h enthalpy $(\mathrm{J} / \mathrm{kg})$

M molecular weight $(\mathrm{kg} / \mathrm{kmol})$

n particle/droplet number density

$\mathrm{P}_{\mathrm{i}} \quad$ oil species

p pressure $(\mathrm{Pa})$

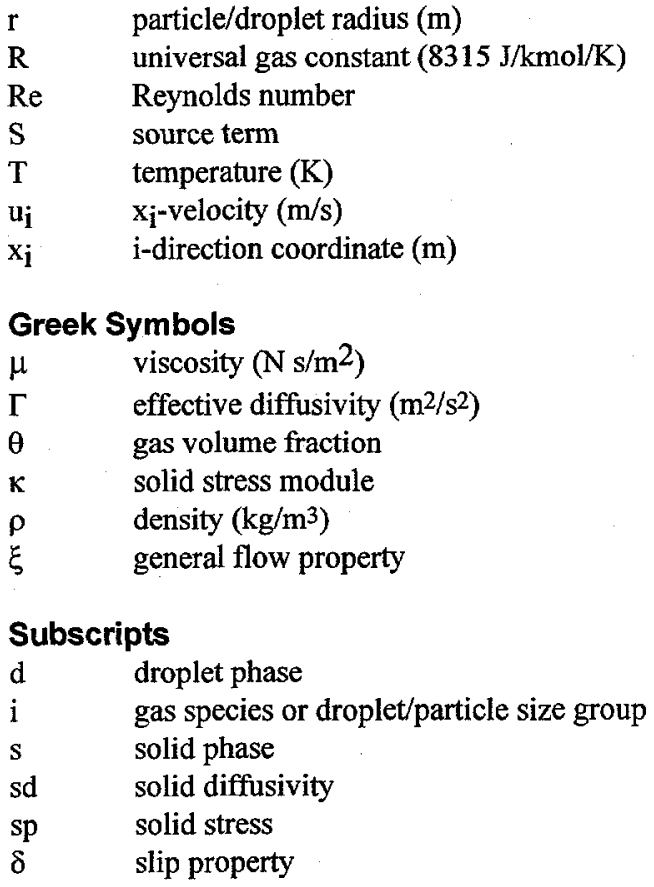

\section{INTRODUCTION}

Fluid Catalytic Cracking (FCC) technology was developed in the 1940s. Since then, it has become the refinery industry's most important process to convert crude oil to more valuable products such as gasoline. Today, the FCC units in U.S. refineries produce about $40 \%$ of the nation's gasoline pool. Over the years, refineries have greatly improved the FCC process to compete in the global markets and meet more stringent environmental regulations. So far, 
the development of catalysts has the most significant impact on the improvement of the FCC technology. In a modern FCC unit, it is essential to optimize product selectivity for each type of feed processed. Recently, refineries have become interested in the advancement of the feed injection system and the development of short residence time riser units (Bienstock et al., 1993). To facilitate and speed up the development of new and/or upgraded FCC systems, detailed knowledge of the relationships between process operating parameters and conditions within the system is needed. Such knowledge can be obtained by analysis of measurements from test units and computer simulation that includes the primary controlling processes of the FCC system.

Computer simulation of an FCC system began with a kinetic calculation based on an assumed or simplified flow field. Weekman and Nace (1970) used a three-lump (feed oil, gasoline, and dry gas) cracking kinetic model to predict gasoline production in an FCC unit. Recently, Nigam and Klein (1993) and Quann and Jaffee (1996) have been developing ways to approach chemical kinetics computation and model building for cracking reaction systems with hundreds or thousands of oil species. These kinetic computations are usually based on simplified or assumed flow fields. With the advancement of computational techniques and computer hardware, computational fluid dynamics (CFD) codes were used to simulate FCC flow. Theologos and Markatos (1993) incorporated Weekman and Nace's lumped kinetic model into a CFD code to simulate FCC riser reactors. The simulation included two-phase flow (gas and particle) and two cracking reactions of three lumped species: oil, gasoline, and dry gas. The code was used to predict engineering aspects of a riser reactor, including pressure drop, particle slip velocity, and temperature distribution. Later, Theologos et. al. (1997) extended the riser flow simulation with a ten-lump kinetic model. A separate CFD code was developed at Argonne National Laboratory (ANL) for the simulation of FCC riser reactors (1996). The ANL code included three-phase (gas, liquid, and particle) flow and a four-lump kinetic model developed by Dave et al. (1993). Later, the code was expanded to include a general kinetic calculation for many product species (1997). This code has been validated with pilot-scale data and used to predict pressure drop, temperature, species/catalyst distributions, and droplet evaporation rates of various FCC riser reactors.

Gas-liquid-solid interactions in an FCC unit are among the most interesting and difficult areas for the development of advanced FCC systems. The ANL code was used to investigate the effects of such complex interfacial interactions on FCC riser hydrodynamics and product yields. This paper reports some results of the investigation.

\section{THEORETICAL APPROACH}

The ANL code is a multi-phase, multi-species, turbulent reacting flow simulation code. A version of the code called the Integral CracKing FLOw Simulation, or ICRKFLO, was specifically written for the FCC riser flow simulation.

A typical FCC unit includes three major components: a riser reactor, a stripper/separator, and a regenerator. Figure 1 shows a simple sketch of the FCC unit. A spray of feed oil is injected into the riser to be converted to lighter oil products. Catalyst particles that are used to vaporize oil droplets and enhance the conversion process are transported to the bottom of the riser reactor from a regenerator. A small amount of inert gas is needed to lift particles in the entrance region of the riser. Oil droplets are vaporized when heated to the boiling point. Then, oil vapor is cracked into various lighter oil products by catalyst and heat. Coke is a by-product of the cracking processes, and it deposits on the catalyst surface. Coke deposition lowers the activity of catalyst particles. The end of the riser is connected to a separator, in which oil products and spent catalyst particles (covered with coke) are separated. Oil products are sent to a distillation column for further processing, and the spent particles are transported to the regenerator in which the coke deposit is burned off with air. After burning off the coke deposit, the heated catalyst particles regain the catalytic activity. The regenerated catalyst is then recycled back to the riser reactor for the next run of cracking process. At present, the flow simulation focuses on the riser flow.

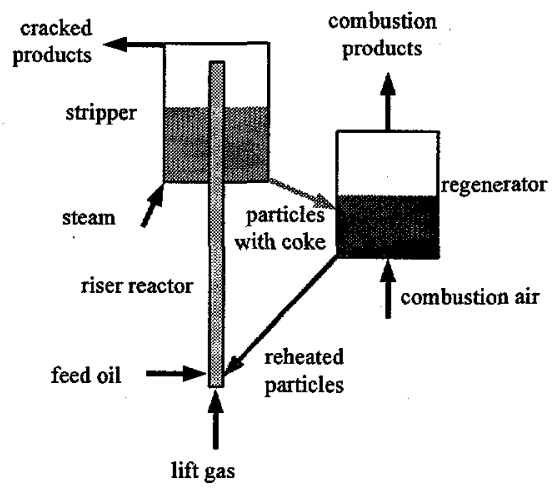

Figure 1 A Typical FCC Unit

In a riser, there are three major processes: mixing, vaporization, and cracking reactions. Mixing encompasses the combined effects of interfacial interactions (momentum and heat transfer between phases), flow convection and turbulent diffusion of gas, oil droplets, and catalyst particles. During the mixing process, the heat carried by the catalyst particles is transferred to the gas and the oil droplets. Generally, the catalyst is heated up to a temperature much higher than the boiling point of the feed oil, and the catalyst mass flow is much larger than the oil flow. Consequently, the vaporization process is dominated by boiling and controlled by the heat transfer rate to oil droplets. During vaporization, a liquid oil droplet releases oil vapor in the presence of hot catalyst particles. Following vaporization, cracking takes place. Feed oil vapor contacts catalyst particles, and the cracking reactions on the catalyst surface convert the feed oil vapor to numerous light oil species and dry gas. Coke is a by-product of the process.

To include all of the oil species in the cracking reactions in a hydrodynamic computation is extremely difficult due to numerical stiffness problems. ICRKFLO uses a hybrid technique to compute both hydrodynamics and chemical kinetics of a large number of species lumps. The hybrid technique divides the whole FCC flow computation into two steps: (1) a reacting flow calculation and (2) a de-coupled subspecies kinetics calculation. The reacting flow calculation is a typical hydrodynamic flow calculation with a small but sufficient number of lumped species to account for the impact of density change due to reaction on the flow. Depending on the application, tens or hundreds of lumped subspecies can be selected. The subspecies kinetics calculation calculates the reaction and the 
transport of subspecies based on the flow field calculated from the first reacting flow calculation.

\section{First-Step: Reacting Flow Calculation}

The first-step multiphase reacting flow calculation solves for the flow properties of major gaseous species, liquid droplets, and catalyst particles in an FCC riser flow. An Eulerian approach is employed to formulate the governing equations of the flow properties for all three phases. Like gaseous species, liquid droplets and catalyst particles are treated as a continuum in the flow

\section{Gas Flow Formulation}

The cracking reactions in the riser convert heavy oil to lighter products. The flow density changes significantly in a riser. The gas phase formulation includes three oil vapor species to account for the effects of density change. These species are included in a simplified 4-lump kinetic model. The kinetic model considers two cracking reactions with four lumped oil components: three gaseous species (feed oil, light oil, and dry gas) and one solid by-product (coke). Feed oil $\left(\mathrm{P}_{\mathrm{o}}\right)$ consists of those oil species of a boiling point higher than $500 \mathrm{~K}$. Light oil $\left(\mathrm{P}_{1}\right)$ includes those species with a boiling point lower than $500 \mathrm{~K}$ and a carbon number higher than 5. Dry gas $\left(\mathrm{P}_{\mathrm{g}}\right)$ includes oil vapor of carbon number $C_{5}$ and below. Coke $\left(C_{k}\right)$ is mostly carbon. The selection of these oil lumps may vary according to the feed stock and riser operating conditions.

The properties of the gas flow include pressure $p$, density $\rho$, temperature $T$, enthalpy $h$, species concentration $f_{i}$, and velocities $\left(u_{i}\right)$. Lift gas species (nitrogen and steam) are also included in the gas flow calculation. Subscript $i$ of the concentration variable $f_{i}$ represents feed oil vapor, light oil vapor, dry gas, nitrogen, or steam. These flow properties are governed by the state equations and the conservation equations. Assuming gas species are all simple ideal gas, the state equations include the ideal gas equation (1) and the caloric equation (2).

$$
\begin{aligned}
& p=\rho R T \sum_{i}\left(\frac{f_{i}}{M_{i}}\right) \\
& h=\sum_{i} f_{i} C p_{i}\left(T-T_{o}\right)
\end{aligned}
$$

In equation (1), $R$ is the universal gas constant and $M_{i}$ is molecular weight of species $i$. In the equation (2), $\mathrm{C}_{\mathrm{pi}}$ is the specific heat of species $I$ and $T_{0}$ is a reference temperature.

The conservation equations include the continuity, the momentum, energy, and species equations. These equations can be expressed in a common form:

$$
\sum_{\mathrm{i}=1}^{3} \frac{\partial}{\partial \mathrm{x}_{\mathrm{i}}}\left(\theta \rho \mathrm{u}_{\mathrm{i}} \xi-\Gamma_{\xi} \frac{\partial \xi}{\partial \mathrm{x}_{\mathrm{i}}}\right)=\mathrm{S}_{\xi}
$$

in which $\xi$ is a general gas flow property, $x_{i}$ are coordinates, $\theta$ is gas volume fraction, $\Gamma$ is effective diffusivity, and $S_{\xi}$ is the sum of source terms. The general gas flow property is a constant 1 for the continuity equation, $u_{i}$ for the $x_{j}$-momentum equation, $h$ for the energy equation, and $f_{i}$ for the species equations. The effective diffusivity is calculated from both laminar and turbulent viscosities and turbulent viscosity is determined from a k- $\varepsilon$ model (see Multiphase k- $\varepsilon$ Turbulent Model section).
The source terms of the governing equations are generally derived from phenomenological models. The continuity equation has a source term accounting for droplet evaporation. The evaporation rate is calculated in the droplet evaporation model (see Spray Evaporation Model section). The momentum equations have source terms for the drag forces from droplets and particles and the enthalpy equation has source terms for the heat transfer to/from droplets and particles. The drag forces and heat transfer rates are calculated in the interfacial model (see Interfacial Interaction Models section). The species equations for the feed oil and dry gas have source terms to account for the consumption of feed oil and the generation of dry gas from the cracking reactions. The species consumption/generation terms are calculated in the kinetic model (see Time-Integral Lumped Cracking Model section). The governing transport equations for the inert gases have no source terms. The light oil concentration is obtained from the algebraic species conservation equation (4) after the feed oil, dry gas, and inert gas equations are solved.

$$
\sum_{i=g a s} f_{i}=1
$$

\section{Liquid Flow Formulation}

Feed oil is injected into the riser in sprays. Oil droplets in a spray generally have many sizes. ICRKFLO divides oil droplets into various size groups. Droplets of a size group $\mathrm{k}$ are treated as a continuum flow. The droplet number density $n_{k}$, temperature $T_{k}$, and velocities $\left(u_{\mathrm{d}, \mathrm{k}, \mathrm{i}}\right)$ of the size group are determined from the conservation equations of mass, momentum, and energy. These equations can be expressed in a common form:

$$
\sum_{\mathrm{i}=1}^{3} \frac{\partial}{\partial \mathrm{x}_{\mathrm{i}}}\left(\mathrm{n}_{\mathrm{d}, \mathrm{k}} \mathrm{u}_{\mathrm{d}, \mathrm{k}, \mathrm{j}} \xi-\Gamma_{\xi} \frac{\partial \mathrm{n}_{\mathrm{d}, \mathrm{k}} \xi}{\partial \mathrm{x}_{\mathrm{i}}}\right)=\mathrm{S}_{\xi}
$$

in which $\xi$ is a general droplet property, $\Gamma$ is the droplet diffusivity resulting from interaction with turbulence in the gas phase, and $S_{\xi}$ is the sum of source terms.

The droplet number density equation has a sink term for the evaporation rate of droplets. The evaporation rates of various size groups are calculated in the droplet evaporation model (see Spray Evaporation Model section). The momentum equations have source terms for the drag force from gas and particles, and the energy equation has source terms for the heat transfer from gas and particles. The drag forces and heat transfer rates are calculated in the interfacial model (see Interfacial Interaction Models section).

\section{Particle Flow Governing Equations}

The formulation of the particle flow is similar to that of the liquid flow. Catalyst particles are divided into various size groups. Particles of each size group $\mathrm{k}$ are treated as a continuum flow. The particle number density $n_{k}$, temperature $T_{k}$, and velocities $\left(u_{p, k, i}\right)$ of the size group are solved from the conservation equations of mass, momentum, and energy. A special particle property for the FCC flow simulation is the coke concentration $C_{k}$. Coke generated from the cracking reactions precipitates on the surface of catalyst particles. A transport equation is needed for coke. The conservation and transport equations are all expressed in a common form similar to equation (5). 
The particle number density equation has no source term. The particle momentum equations have source terms for the drag forces from gas and droplets and the energy equation has source terms for the heat transfer to/from gas and droplets. The drag forces and heat transfer rates are calculated in the interfacial model. The coke equation has a source term to account for the generation of coke from reactions. The coke generation rate is calculated in the kinetic model (see Time-Integral Lumped Cracking section).

\section{Phenomenological Models}

Phenomenological models include a particle-solid interaction models, interfacial interaction models, a time-integral lumped cracking model, a spray evaporation model, and a multi-phase $\mathrm{k}-\varepsilon$ turbulence model.

\section{Particle-Solid Interaction Models}

In a dense flow region, a moving particle tends to collide with neighboring particles and the collisions cause the particles to diffuse across the flow stream. Since the particle diffusion process is similar to that of gas molecules, a solid diffusivity can be derived. Since particle collision frequency is proportional to local particle mass flux, the solid diffusivity term can be derived as:

$$
\mathrm{S}_{\mathrm{sd}_{\mathrm{lx}}}=\mu_{\mathrm{sd}} \frac{\partial\left(\mathrm{nu} \mathrm{u}_{2 \mathrm{~s}}\right)}{\partial \mathrm{x}_{1}}
$$

The particle diffusivity term is added to the particle momentum equations as a source term. The collisions between particles and the wall also cause the particle flow to lose momentum. A solid shear stress term is used in the particle momentum equations.

If particles are packed, particles are directly in contact with the neighboring particles. A solid pressure is exerted on the particles. The solid pressure is generally assumed to be a function of local solid volume fraction when solid fraction exceeds a packed value.

$$
\mathrm{S}_{\mathrm{sp}, \mathrm{x}}=\frac{\partial}{\partial \mathrm{x}}\left[\kappa\left(\theta_{\mathrm{s}}-\theta_{\mathrm{sp}}\right)\right] \quad \text { if } \theta_{\mathrm{s}}>\theta_{\mathrm{sp}}
$$

The solid pressure term, Equation (7), is added to the particle momentum equations as a source term. Lyczkowski et. al. (1994) used local solid volume fraction to calculate solid pressure in a study of gas/particle flow in fluidized bed reactors. This approach is commonly used for the simulation of gas/particle flows, but when particle volume fraction is near the packed state, a small change in calculated solid volume fraction results in huge changes in solid stress, which can easily cause numerical instability and divergence of the computation. An alternative approach that is much more numerically stable is to calculate the solid volume fraction from an accumulated solid pressure.

\section{Interfacial Interaction Models}

Interfacial models were developed for the interactions between phases. The interactions include the exchanges of mass, momentum, and energy between phases.

In the dilute flow region, oil droplets and catalyst particles are driven mainly by the drag force from the gas flow. An empirical Reynolds formula correlating the drag force with local flow properties and velocity difference is used to calculate the interfacial drag force. The drag force is used in the source terms of the gas, liquid, and solid momentum equations.

$$
C_{d}=\frac{24}{\operatorname{Re}_{s}} \frac{\left(1+0.15 \operatorname{Re}_{s}^{0.687}\right)}{1} \text { and } \operatorname{Re}_{s}=\frac{2 \rho\left|u_{\delta}\right| r}{\mu}
$$

Catalyst particles are the principal heat carriers, supplying energy to vaporize the oil droplets. An empirical Nusselt formula is used to calculate the heat transfer between particles and gases, and between droplets and gas. The heat transfer rate is used in the source terms of the gas, liquid, and solid energy equations.

\section{Time-Integral Lumped Cracking Model}

The lumped cracking model was developed based on the lumped kinetics modeling works by Dave et al. (1993) and the integral reacting-flow time-scale-conversion method by Chang and Lottes (1993). The two cracking reactions of the kinetic model are reaction (a) that converts feed oil to light oil, dry gas, and coke; and reaction (b) that converts light oil to dry gas and coke. These reactions are denoted as follows:

$$
\begin{aligned}
& \mathrm{P}_{\mathrm{o}} \longrightarrow \mathrm{a}_{1} \mathrm{P}_{\ell}+\mathrm{a}_{2} \mathrm{P}_{\mathrm{g}}+\mathrm{a}_{3} \mathrm{C}_{\mathrm{k}} \\
& \mathrm{P}_{\ell} \longrightarrow \mathrm{b}_{1} \mathrm{P}_{\mathrm{g}}+\mathrm{b}_{2} \mathrm{C}_{\mathrm{k}}
\end{aligned}
$$

In these reactions, the stoichiometric coefficients, $a_{1}, a_{2}, a_{3}, b_{1}$, and $\mathrm{b}_{2}$, are expressed in mass fractions.

Many reacting flow calculations experience severe numerical stiffness problems due to the difference of the flow and the reaction time scales. A time scale bridging integral as opposed to differential approach was developed to overcome these numerical problems. The kinetic model is used to determine the consumption rate for the feed oil species, and the generation rates for light oil, dry gas, and coke. The species consumption/generation rates are used in the source terms of the gas species equations.

\section{Spray Evaporation Model}

Liquid feed oil needs to be vaporized so the oil vapor may be cracked into products. A droplet evaporation model was based on the fundamental physics of stationary single droplet evaporation and then modified for large groups of droplets in a connective environment. The model is used to calculate the local evaporation rate of the droplets. The evaporation rate is used in the source terms of the gas continuity and droplet number density equations. More details of the model were given in a separate paper (Chang, et. al. 1997).

\section{Multi-phase k- $\varepsilon$ Turbulent Model}

A turbulent flow consists of a spectrum of rotational eddies. The eddies, having a size ranging from a tiny, molecular sized rotation to one the size of the flow, can effectively transport and mix species, momentum, heat, and other transportable components or properties of the flow. The mixing rates of the turbulent motion are generally several orders of magnitude greater than those of the molecular diffusion. Patankar and Spalding (1972) developed a turbulence model employing the turbulent kinetic energy $k$ and its dissipation rate $\varepsilon$ for single phase flows. Two additional transport equations, like Equation (5), for these turbulent parameters were introduced. By solving these two transport equations, the turbulent diffusivity can be determined from the values of $k$ and $\varepsilon$. Among others, Zhou and Chiu (1983) later modified the turbulence model 
for multi-phase flows and an enhanced version of their model is used in the ICRKFLO code.

In the first-step reacting flow calculation, the governing equations of the flow field of an FCC riser are solved. In the riser, local flow properties such as velocity, temperature, catalyst particle number density, feed droplet number density, evaporation rate, and major species concentrations are calculated. These flow properties are then used to perform a detailed kinetics calculation.

\section{Second-Step: Subspecies Kinetics Calculation}

The major gaseous species in the above-mentioned reacting flow calculation are lumped into broad categories: feed oil, light oil, and dry gas. However, within these oil species lumps exist a very large number of oil subspecies produced from numerous kinetic reactions in the riser. These subspecies are not solved in the firststep flow calculation to avoid numerical stiffness problems. After the first-step calculation, the transport equations of these kinetic subspecies can be solved on the pre-determined flow field. Free from the interactions of the pressure and velocity fluctuations, the calculation of the partially de-coupled species transport equations becomes very stable numerically. A more detailed description of the second step subspecies calculation is given in (Chang et al., 1997).

\section{NUMERICAL SCHEME}

From the previous sections, a set of governing equations is derived to solve for the velocity, pressure, density, temperature, and species concentration of an FCC riser flow. ICRKFLO adopts a control volume approach to convert the governing equations to algebraic equations on a discretized grid system. The grid system is staggered, consisting of three grids: an $\mathrm{x}$-momentum grid for the gas phase $\mathrm{x}$-momentum equation, a gas phase $\mathrm{y}$-momentum grid, and a scalar grid for all the other equations. The algebraic equations are solved iteratively with proper boundary conditions. In the calculations, Patankar's SIMPLER computational scheme (1980) is used to solve the pressure linked momentum equations.

A grid sensitivity study was conducted to select a grid system that gives independent numerical results to three significant decimal places regardless of further grid refinement in order to conserve computational time and still provide adequately accurate results. An important feature of the control volume approach used by the ICRKFLO code is that it is conservative in terms of mass, energy, species, and all variables solved for via the transport equations, both locally and globally to a very high degree regardless of grid size.

The simulated riser flow includes five gas species, five droplet size groups, a single particle size group, and a coke species carried by particles. In this computer code, a calculation is considered to have converged if the local and global mass balances of the three phases are smaller than a set of predetermined criteria. For this simulation, convergence criteria, defined by average mass residual of all computational cells, are 10-10 (in dimensionless form, normalized by the gas mass flow rate) for the gas phase and $10^{-7}$ for both the liquid and solid phases. Generally in this application, with reasonable boundary conditions (inlet flow rates etc.), a converged solution can be obtained in about 2000 iterations. Each iteration includes ten gas phase, three liquid, and three solid phase calculations. On a Pentium ${ }^{\mathrm{TM}} 90$ personal computer with 16 megabytes of random access memory, using a 32-bit FORTRAN compiler, this computation takes about two hours. The subspecies calculation is generally much faster than the flow calculation depending on the number of subspecies to be calculated.

\section{VALIDATION}

The ICRKFLO code has been validated by comparing calculated flow properties against several sets of experimental and test data. The flow properties used for comparisons include velocities, residence time, pressure drop, temperature, particle volume fraction, and most importantly product yields. The comparisons show good agreement between the calculated and measured flow property values. Some of the validation results have been reported in previous works (Chang et al., 1996, and Chang et al., 1997).

The particle interaction models in ICRKFLO have been extensively validated by comparing the computational results with industrial measurements. Pressure and solid volume fraction comparisons have been made with measurements from a pulverized coal pipeline [Golchert et. al., 1998], with results published in the literature, and with proprietary results provided by industry for both hot and cold flow in FCC units. In all these cases, the computational results compare very favorably with the measured data.

\section{RESULTS AND DISCUSSION}

This study investigates the effects of both the particle interaction models inside the code and the effect of inlet particle conditions on the yields from an FCC riser. To determine the effect of the particle models used in the code, a comparison was made between the computed results with the models present and the computed results with the models turned off. The models that directly relate to this study are the particle-particle interaction model and the particle-wall interaction model. The first model determines how well the particles diffuse in the radial direction while the second model accounts for the slowing down of the particles as they move along the wall. This slowing down is caused by wall friction. In the second portion of this work, other parameters relating to the inlet conditions of the particles were analyzed.

The first step in this investigation was to establish a baseline case to which all other cases will be compared. To avoid proprietary issues, a generic riser with a diameter of eight inches was used. This riser has the catalyst injected on one side at the bottom and the oil injected from both sides a little farther up the riser. This configuration was not changed throughout the entire work. Also, a set of kinetics constants was generated for the ICRKFLO3 simulation with a relatively low total conversion. This allows for future optimization of the riser configuration. For this study, the total catalyst mass flux $(12.11 \mathrm{~kg} / \mathrm{s})$, the catalyst-to-oil ratio $(8.00)$ and the riser exit temperature $(811.0 \mathrm{~K})$ were held constant to allow the focusing of attention on those parameters being varied. These chosen values are within the normal operating parameters of a commercial FCC unit.

To determine how well a riser is operating, a figure of merit must be established that will give some indication as to whether the proposed change (as calculated computationally) will result in an actual improvement in the riser operation. For this work, the figure of merit will simply be the total amount of feed oil left uncracked when exiting the riser. The lower this value, the better the riser is operating. Less feed oil implies more light oil (gasoline) and dry gas and thus higher total conversion. 
For the results are shown in Figures 2 through 5., 'a' indicates the results with the particle models present, and ' $b$ ' shows the results with the particle models turned off. This will allow a visual comparison of the effects of these models. In general, the darker the color on these plots, the larger the variable being plotted (number density, velocity, etc.)

Since the catalyst provides the heat necessary to vaporize the oil droplets, its spatial distribution in the riser will have a strong impact on the conversion of the feed. Figure 2 shows the particle number density throughout the riser. In Figure $2 a$, the particles build up along the walls of the riser as the exit of the riser is reached. This creates a U-shaped distribution that has been observed in industry and in experiments. This U-shaped distribution is attributed to the effect of both particle models. The particles in the center diffuse towards the wall of the riser and, once against the wall, the axial motion of these particles is slowed by the effect of the particle-wall model (friction between the particles and the wall). Without these models, a different particle distribution is formed, as is shown in Figure $2 \mathrm{~b}$. Here, the particles do not spread out and form the Ushaped distribution. Essentially, the particles follow the velocity distribution of the gas.

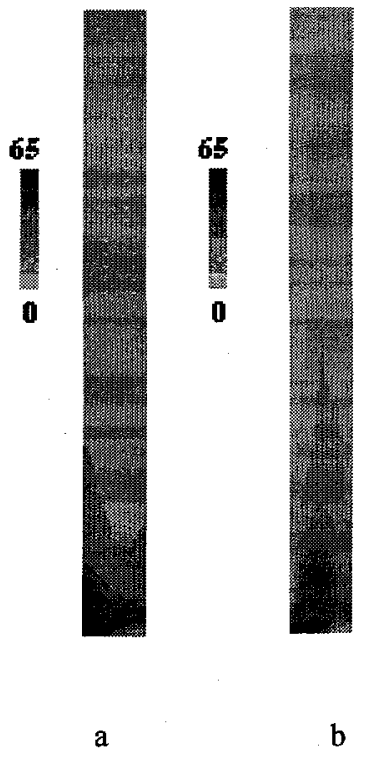

Figure2 Particle Number Density Distribution in the Riser with Particle Interaction Models (a) and without these Models (b)

Because the heat from the catalyst vaporizes the oil droplets, the catalyst number density will affect where and how fast the droplets are evaporated. As was seen in Figure 2a, with the models present, there will be more catalyst closer to the walls of the riser. Since the feed oil is injected along the sides of the riser, there will be quicker evaporation of the oil droplets than in the case where the particle interaction models are not present. In the case without the particle models, there is more catalyst in the center of the riser, and thus the droplets will be injected and move towards the exit of the riser before beginning to evaporate. Figure $3 \mathrm{a}$ shows that the droplets are not present near the wall of the riser since they have been evaporated by the hot catalyst while in Figure 3b, there are droplets near the wall of the riser where catalyst is sparsely distributed. Since oil must be in gaseous form to be cracked into the various, lighter products, the rate of droplet evaporation will directly correlate towards the total riser performance. For this particular case, by not including the particle interaction models, the total amount of conversion decreases by approximately $5 \%$, thus emphasizing the importance of these models.

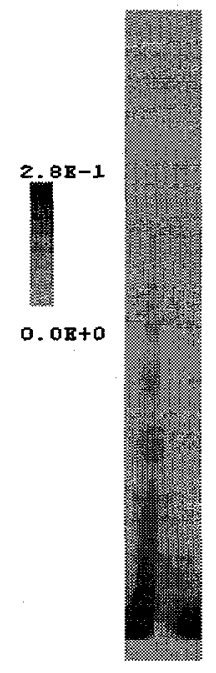

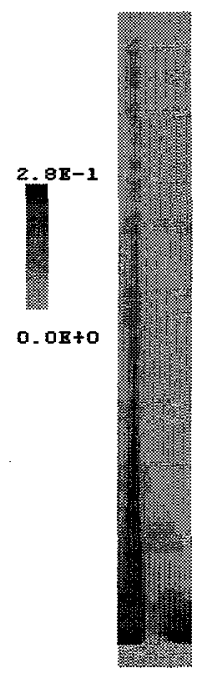

b
Figure 3 Droplet Number Density with Particle Interaction Models (a) and without Particle Interaction Models (b)

Not only does the average exit conversion change with the inclusion of the particle models, the local feed oil concentration is changed also. Figure 4 displays the feed oil in the riser as a percentage of total products. Ideally, the amount of feed oil exiting the riser should be minimized since the feed oil should be cracked into more valuable products, such as light oil and dry gas. Figure 4a shows that there is less feed oil at the exit when the particle models are present while Figure $4 \mathrm{~b}$ shows less cracking when the models are not present. This verifies the assumption that more complete droplet evaporation leads to better cracking results. 


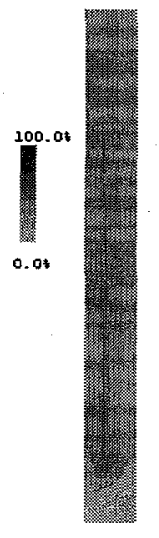

a

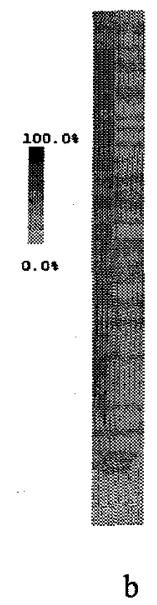

Figure 4 Feed Oil Yields with the Particle Models Present (a) and without the Models Present (b)

Now that the importance of these models has been established, an investigation was performed on those particle inlet conditions that can be controlled by the rider operator. Clearly, a riser operator can control how fast and at what angle the catalyst is injected into the riser. Figure 5 shows the effects of inlet particle velocity on conversion. A smaller feed oil percentage indicates that more feed oil is being converted into products, thus giving a larger figure of merit. In Figure 5, the amount of feed oil conversion increases with increasing catalyst inlet velocity. The higher injection velocity helps promote better mixing. This better mixing between particles and droplets results in increased in evaporation, and more feed oil conversion into products.

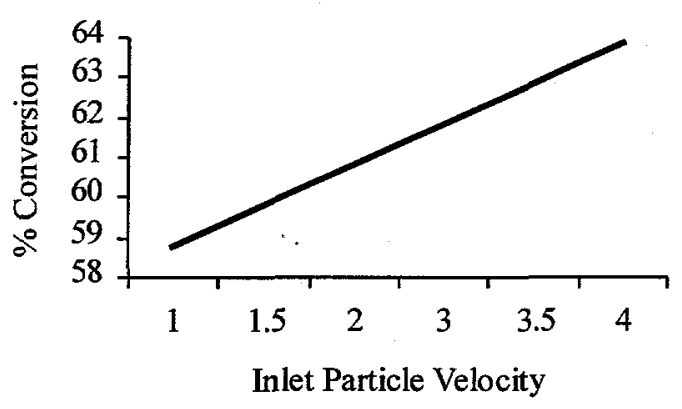

Figure 5 Effects of Inlet Particle Velocity on Yields

An explanation of Figure 6 demonstrates how the particle number density distribution will affect total conversion. In Figure 6a, (low injection velocity) particles remain concentrated around the injection point and they are swept away by the momentum of the lift gas before many of the particles reach the middle of the riser. In Figure $6 \mathrm{~b}$, the particles are moving at a faster rate when they are injected, and they are able to travel farther across the diameter of the riser. They enter the riser with more momentum in the radial riser direction, and it takes longer for the lift gas to overcome this momentum and turn their flow in the axial direction. This gives a more even particle distribution across the injection region of the riser. As the particles flow to the outlet and travel past the droplet injection points, the particles are able to interact with more droplets. This better mixing allows more heat to transfer from the particles to the droplets, resulting in more complete evaporation and, ultimately, better conversion of feed oil into products. Velocity can be increased to a certain limit before the injected particles hit the opposite wall of the riser where they may begin to accumulate. This reduces the effect of the increased mixing and causes the conversion rate to decrease.

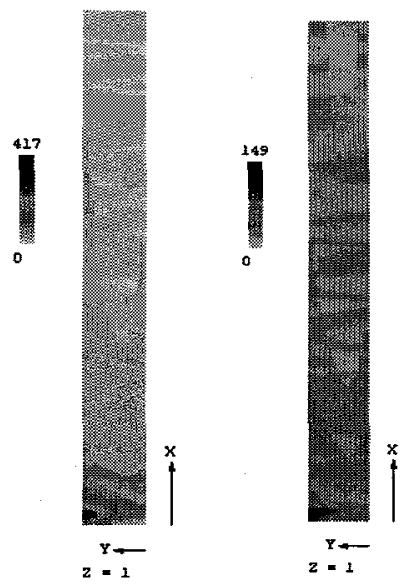

(a) lower velocity $\quad$ (b) higher velocity

Figure 6 Particle Number Density Distribution

As was previously mentioned, injection angle is also under the control of the operator. Figure 7 shows the effects of inlet injection angle on conversion rates. In this figure, the numbers of the ordinate refer to the angle between the vertical and the injection angle. Thus, an injection angle of $90^{\circ}$ injects the catalyst straight across the riser. In all cases, the mass flux rates and the overall velocity of the particles were kept constant, and the particle number density and the velocities in the radial and axial riser directions were allowed to fluctuate. The highest conversion of feed oil occurs when the particles are being injected perpendicular to the gas flow. However, as can be seen from the figure, the effect of injection velocity is negligible when compared with that of the injection velocity.

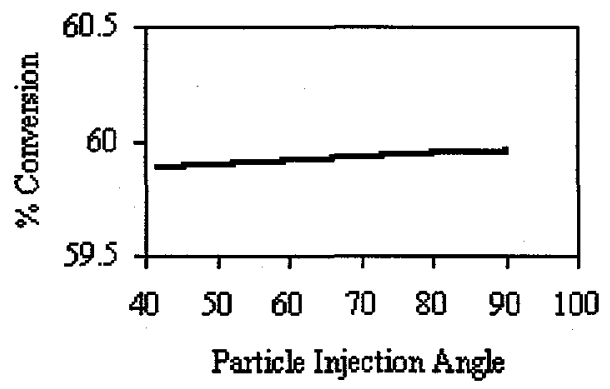

Figure 7 Effect of Particle Injection Angle on Yields

Finally, the riser operator has some control over the average particle size. The effect on conversion of the average particle size is shown in Figure 8. The conversion of feed oil increases as particle size is increased. Particle mass flux is kept the same for all cases. 
The amount of particle surface area is reduced when larger catalyst particles are used and this leads to less cracking between the particles and the evaporated droplets. However, this disadvantageous effect is overcome by increased heat transfer from the particles to the droplets. The larger particles carry more heat (per particle) than the smaller particles. However, the overall effect on total conversion is still relatively small (less than one percent).

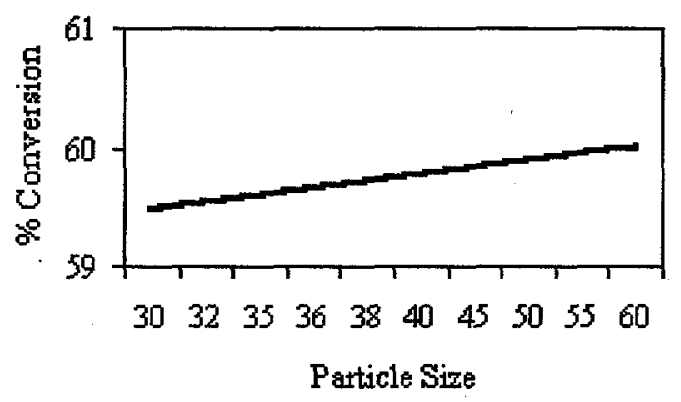

Figure 8 Effect of Particle Size on Yields

\section{CONCLUSION}

The code was used to study the effect particle interactions and particle inlet conditions in a FCC riser. Results show that the particle-particle interaction model and the particle-wall interaction model are needed to produce results that have been observed both by industry and in experiments. In addition, the amount of cracking significantly decreases when these models are not present, thus indicating the importance of having the proper, physics-based models in a CFD simulation.

The results from the parametric studies indicate that those inlet conditions that maximize the mixing of the particles maximize the cracking in the riser. The optimal mixing is affected by the inlet velocity of the particles, by the injection angle of the particles, and by the size of the particles. In the optimum case, the inlet particle velocity must be sufficient to evenly disperse the particles across the inlet of the riser, the particles are injected perpendicularly to the flow of the lift gas, and the particles are large in diameter.

\section{ACKNOWLEDGMENTS}

This work was supported by U.S. Department of Energy, Office of Energy Efficiency and Renewable Energy and the Office of Industrial Technologies, under Contract W-31-109-ENG-38. This work was also supported by the National Science Foundation, under Award \#9753287.

\section{REFERENCES}

Bienstock, M.G., D.C. Draemel, P.K. Ladwig, R.D. Patel, and P.H. Maher, "A History of FCC Process Improvement Through Technology Development and Application," AIChE Spring National Meeting, Houston, TX, (1993).
Chang, S.L., and S.A. Lottes, "Integral Combustion Simulation of a Turbulent Reacting Flow in a Channel with Cross-Stream Injection," Numerical Heat Transfer Part A, 24(1):25-43 (1993).

Chang, S.L., S.A. Lottes, C.Q. Zhou, and M. Petrick, A Hybrid Technique for Coupling Chemical Kinetics and Hydrodynamics Computations in Multi-Phase Reacting Flow Systems, HTD-Vol. 352, Proceedings of the ASME Heat Transfer Division 2:149-158, the 1997 International Mechanical Engineering Congress and Exposition, Dallas, TX (November 16-21, 1997).

Chang, S.L., S.A. Lottes, C.Q. Zhou, and M. Petrick, Evaluation of Multiphase Heat Transfer and Droplet Evaporation in Petroleum Cracking Flows, HTD-Vol. 335, Proceedings of the ASME Heat Transfer Division 4:17-27, International Mechanical Engineering Congress and Exposition, Atlanta, GA (November 17-22, 1996).

Dave, N.C., G.J. Duffy, and P. Udaja, "A Four-Lump Kinetic Model for the Cracking/Coking of Recycled Heavy Oil," Fuel, 72(9):1331-1334, (1993).

Golchert, B.M., S.L. Chang, and M. Petrick, "Investigation of Particle/Gas Flow Characteristics in Long Pipelines," presented at the Topical Conference on Advanced Technologies for Particle Processing at the AIChE 1998 Annual Meeting (November 15-20, 1998).

Lyczkowski, R.W., J.X. Bouillard, S.L. Chang and S.A. Lottes State-of-the-Art Review of Computational Fluid Dynamics Modeling for Fluid-Solids Systems, the International Symposium on Parallel Computing in Multiphase Flow Systems Simulations, 1994 ASME Winter Annual Meeting, Chicago, IL (November 6-11, 1994).

Nigam, A., and M.T. Klein, "A Mechanism-Oriented Lumping Strategy for Heavy Hydrocarbon Pyrolysis: Imposition of Quantitative Structure-Reactivity Relationships for Pure Components," Ind. Eng. Chem. Res., 32:1297-1303,(1993).

Patankar, S.V. and D.B. Spalding, "A Calculation Procedure for Heat, Mass and Momentum Transfer in Three-dimensional Parabolic Flows", Int. J. Heat Mass Transfer, vol. 15, p.1787 (1972).

Patankar, S.V., "Numerical Heat Transfer and Fluid Flow", Hemisphere, Washington, D.C. (1980).

Quann, R.J., and S.B. Jaffee, "Building Useful Models of Complex Reaction Systems in Petroleum Refining," Chemical Engineering Science, 51(10):1615-1635, (1996).

Theologos, K.N. and N.C. Markatos, "Advanced Modeling of Fluid Catalytic Cracking Riser-Type Reactors," AIChE Journal, 39(6):1007-1017, (1993).

Theologos, K.N., I.D Nikou, A.I. Lygeros, and N.C. Markatos, "Simulation and Design of Fluid Catalytic-Cracking Riser-Type Reactors," AIChE Journal, 43(2): 486-494, (1997).

Weekman, V.W. and D.M. Nace, "Kinetics of Catalytic Cracking Selectivity in Fixed, Moving, and Fluid Bed Reactors," AIChE Journal, 16(3):397-404, (1970).

Zhou, X.Q., and H.H. Chiu, "Spray Group Combustion Processes in Air Breathing Propulsion Combustors," AIAA/SAE/ASME 19th Joint Propulsion Conference, Seattle, Washington, AIAA-83-1323, (1983). 